This item was submitted to Loughborough's Research Repository by the author.

Items in Figshare are protected by copyright, with all rights reserved, unless otherwise indicated.

\title{
Should electric fans be used during a heat wave?
}

PLEASE CITE THE PUBLISHED VERSION

http://dx.doi.org/10.1016/j.apergo.2014.07.013

\section{PUBLISHER}

Elsevier Science Ltd.

\section{VERSION}

AM (Accepted Manuscript)

\section{PUBLISHER STATEMENT}

This work is made available according to the conditions of the Creative Commons Attribution-NonCommercialNoDerivatives 4.0 International (CC BY-NC-ND 4.0) licence. Full details of this licence are available at: https://creativecommons.org/licenses/by-nc-nd/4.0/

\section{LICENCE}

CC BY-NC-ND 4.0

\section{REPOSITORY RECORD}

Jay, Oliver E., Matthew N. Cramer, Nicholas M. Ravanelli, and Simon Hodder. 2014. "Should Electric Fans Be Used During a Heat Wave?”. Loughborough University. https://hdl.handle.net/2134/18684. 
Should electric fans be used during a heat wave?

Ollie Jay ${ }^{1,2} \bowtie$ Matthew N. Cramer ${ }^{2}$, Nicholas M. Ravanelli ${ }^{2}$ and Simon G. Hodder ${ }^{3}$

${ }^{1}$ Thermal Ergonomics Laboratory, Exercise and Sport Science, Faculty of Health Sciences, University of Sydney, 75 East St, Lidcombe, NSW 2141, AUSTRALIA

${ }^{2}$ School of Human Kinetics, University of Ottawa, CANADA, K1N 6N5

${ }^{3}$ Environmental Ergonomics Research Centre, Loughborough University, Leics, UNITED

KINGDOM, LE11 3TU.

Address for correspondence:

Dr. O. Jay $\square$

Exercise and Sport Science,

Faculty of Health Sciences,

University of Sydney,

75 East St,

Lidcombe, NSW 2141

Australia

e-mail: ollie.jay@sydney.edu.au 


\begin{abstract}
.
Heat waves continue to claim lives, with the elderly and poor at greatest risk. A simple and cost-effective intervention is an electric fan, but public health agencies warn against their use despite no evidence refuting their efficacy in heat waves. A conceptual human heat balance model can be used to estimate the evaporative requirement for heat balance, the potential for evaporative heat loss from the skin, and the predicted sweat rate, with and without an electrical fan during heat wave conditions. Using criteria defined by the literature, it is clear that fans increase the predicted critical environmental limits for both the physiological compensation of endogenous/exogenous heat, and the onset of cardiovascular strain by an air temperature of $\sim 3-4^{\circ} \mathrm{C}$, irrespective of relative humidity $(\mathrm{RH})$ for the young and elderly. Even above these critical limits, fans would apparently still provide marginal benefits at air temperatures as high as $51.1^{\circ} \mathrm{C}$ at $10 \% \mathrm{RH}$ for young adults and $48.1^{\circ} \mathrm{C}$ at $10 \% \mathrm{RH}$ for the elderly. Previous concerns that dehydration would be exacerbated with fan use do not seem likely, except under very hot $\left(>40^{\circ} \mathrm{C}\right)$ and dry $(<10 \% \mathrm{RH})$ conditions, when predicted sweat losses are only greater with fans by a minor amount ( $20-30 \mathrm{~mL} /$ hour$)$. Relative to the peak outdoor environmental conditions reported during ten of the most severe heat waves in recent history, fan use would be advisable in all of these situations, even when reducing the predicted maximum sweat output for the elderly. The protective benefit of fans appears to be underestimated by current guidelines.
\end{abstract}

Keywords: Extreme heat events; Hydration; Air flow Highlights

- The effect of electric fan use on human heat balance during heat waves was modelled - Fans increase critical air temperature for elevated physiological strain by $3-4^{\circ} \mathrm{C}$ - Model suggests fans would not have been harmful during any recent major heat wave 
- Current public health guidance seem to underestimate the evaporative power of fans

- A simple guidance chart on electric fan use for healthcare practitioners is given 


\section{INTRODUCTION}

In the continental United States, the summer of 2012 was the hottest since records began. In 2013, record-breaking ambient temperatures were experienced across large parts of Eastern Australia (January) as well as the Western US (June). These heat waves continue to claim lives, with the elderly, poor and socially isolated at the greatest risk (Hajat et al. 2010). Public health recommendations for effective heat management strategies are absolutely essential to minimize heat-related mortality. A simple and cost-effective intervention is an electric fan. However, governmental public health messaging is often ambiguous and typically warns against their use. The suggested environmental limits for fan use has historically ranged from $32.3^{\circ} \mathrm{C}\left(90^{\circ} \mathrm{F}\right)(35 \%$ relative humidity $(\mathrm{RH}))$ (Wolfe, 2003) to the "high 90s" $\left(96-99^{\circ} \mathrm{F} ; 35.6-37.2^{\circ} \mathrm{C}\right)$ with no RH stated (CDC, 2012). In contrast, a recent Cochrane review concluded that no evidence whatsoever currently exists in the literature supporting or refuting the use of electric fans during heat waves (Gupta et al. 2012). The authors did however suggest that the enhanced evaporation with fan use may lead to an increased risk of dehydration (Gupta et al. 2012).

In order to maintain a fixed core body temperature, the human body must balance the rate at which it produces heat, arising as a by-product of cellular metabolism (approximately $80-100 \mathrm{~W}$ at rest), with the rate at which heat is dissipated to the surrounding environment. Human heat dissipation occurs via dry (i.e. conduction and convection) and latent (i.e. evaporation) avenues of heat transfer. All dry heat transfer follows a temperature gradient, which in this case, is between ambient air and the skin surface. It follows that if air temperature exceeds skin temperature (approximately $35^{\circ} \mathrm{C} ; 95^{\circ} \mathrm{F}$ ) the gradient for dry heat loss is reversed and heat is added to the body instead of lost. Since the vast majority of dry heat exchange occurs via convection, this problem is compounded with additional air movement (such as with a fan). However, the human thermoregulatory system elicits the 
secretion of sweat on to the skin surface which subsequently evaporates, promoting latent heat loss; and the potential for evaporation $\left(\mathrm{E}_{\max }\right)$ is increased substantially with increasing air movement. However, the elevation in $\mathrm{E}_{\max }$ with additional air flow is diminished with increasing ambient humidity. Furthermore, a greater sweat production may be needed to facilitate the greater rate of evaporation required to maintain overall heat balance $\left(\mathrm{E}_{\text {req }}\right)$, and the elderly, who are considered a high risk group during heat waves, may be physiologically restricted (Kenney and Hodgson, 1987). The potentially greater requirement for sweat production with electric fans may also be elevated to the point of exacerbating physiological strain in terms of dehydration (Gupta et al. 2012) and cardiovascular strain.

Using a human heat balance approach and employing parameters defined by the literature, the following can be conceptually determined: i) the various combinations of air temperature and humidity at which an electric fan is counter-protective; ii) the predicted critical environmental limits for elevated cardiovascular strain and thermal strain, with and without an electric fan; and iii) the predicted sweat losses and therefore the risk of dehydration with and without an electric fan.

\section{METHODS}

A conceptual human heat balance approach was used to derive the evaporative requirement for heat balance $\left(\mathrm{E}_{\mathrm{req}}\right)$, the evaporative potential in the ambient environment $\left(\mathrm{E}_{\max }\right)$, and the predicted rate of sweating, with and without an 18 " diameter electrical fan, set at maximum speed, placed at waist height, directly facing an individual at a distance of $1.0 \mathrm{~m}$. The model simulated a younger adult (20 to $40 \mathrm{y}$ ), and an elderly adult ( $>75 \mathrm{y})$, who are lightly clothed, and seated indoors during a heat wave. Combinations of air temperature, (26 to $60^{\circ} \mathrm{C} ; 79$ to $\left.140^{\circ} \mathrm{F}\right)$ and relative humidity $(10 \%$ to $100 \%)$ were used to represent a range of environmental conditions that extend beyond those historically arising during heat waves. 


\section{Conceptual heat balance model - Required evaporation}

The rate of evaporation required for heat balance $\left(E_{\text {req }}\right)$ was calculated using equation 1 (Gagge and Gonzalez, 1996):

$\mathrm{E}_{\text {req }}=\mathrm{M}-\mathrm{W}-(\mathrm{C}+\mathrm{R})-\left(\mathrm{C}_{\text {res }}+\mathrm{E}_{\text {res }}\right)$

Where: $\mathrm{M}$ is metabolic energy expenditure; $\mathrm{W}$ is external work; $\mathrm{C}$ is convective heat loss; $\mathrm{R}$ is radiative heat loss; $\mathrm{C}_{\text {res }}$ is convective loss by respiration; $\mathrm{E}_{\text {res }}$ is evaporative heat loss by respiration. All units are in $\mathrm{Wm}^{-2}$.

The rate of metabolic energy expenditure $(\mathrm{M})$ was set at $65 \mathrm{Wm}^{-2}$ which is equivalent to a person standing (Parsons, 2003). A typical value for $\mathrm{M}$ when seated could be as low as $58 \mathrm{Wm}^{-2}$ (Parsons, 2003), however the highest potential value was selected to represent the worst-case scenario in terms of metabolic heat that must be dissipated to maintain a stable body temperature.

The rate of external work (W) was assumed to be $0 \mathrm{Wm}^{-2}$ since any work on surrounding objects would be negligible (Parsons, 2003).

The combined rate of dry heat transfer by convection $(\mathrm{C})$ and radiation $(\mathrm{R})$ were calculated using equation 2 (Gagge and Gonzalez, 1996):

$$
\mathrm{C}+\mathrm{R}=\frac{\left(t_{s k}-t_{o}\right)}{\left(R_{c l}+\frac{1}{f_{c l} h}\right)}
$$

Where: $t_{s k}$ is mean skin temperature in ${ }^{\circ} \mathrm{C}$; $t_{o}$ is operative temperature in ${ }^{\circ} \mathrm{C}$ which in this case was equal to ambient air temperature; $R_{c l}$ is dry heat transfer resistance of clothing in $\mathrm{m}^{2} \mathrm{~K}$ $\mathrm{W}^{-1} ; f_{c l}$ is clothing area factor (no units) estimated using equation 3 (McCullough and Jones, 1984):

$f_{c l}=1.0+\frac{0.31 R_{c l}}{0.155}$ 
Where: $h$ is the sum of the convective heat transfer coefficient $\left(h_{c}\right)$ in $\mathrm{Wm}^{-2} \mathrm{~K}^{-1}$ and the radiative heat transfer coefficient $\left(h_{r}\right)$ in $\mathrm{Wm}^{-2} \mathrm{~K}^{-1} . h_{c}$ is calculated using Equation 4 (Mitchell, 1974), and $h_{r}$ is calculated using equation 5 (de Dear et al. 1997; Parsons, 2003):

$h_{c}=8.3 v^{0.6}$

Where: $v$ is air velocity in $\mathrm{ms}^{-1}$.

$h_{r}=4 \varepsilon \sigma \frac{A_{r}}{B S A}\left[273.2+\frac{\left(t_{s k}+t_{r}\right)}{2}\right]^{3}$

Where: $\varepsilon$ is the area weighted emissivity of the clothing body surface (assumed to be 1.0); $\sigma$ is the Stefan-Boltzmann constant, $5.67 \times 10^{-8} \mathrm{Wm}^{-2} \mathrm{~K}^{-4} ; A_{r} / B S A$ is the effective radiative area of the body (assumed to be 0.70 for seated individuals (Fanger 1967)); $t_{r}$ is mean radiant temperature in ${ }^{\circ} \mathrm{C}$.

A mean skin temperature $\left(\mathrm{t}_{\mathrm{sk}}\right)$ of $35.5^{\circ} \mathrm{C}$ (Drinkwater et al. 1982; ZahorskaMarkiewicz, 1982) was employed for both young adult and elderly predictions. While the change in $\mathrm{t}_{\mathrm{sk}}$ during a passive heat exposure may actually be $0.5^{\circ} \mathrm{C}$ to $1.0^{\circ} \mathrm{C}$ higher in the elderly (Dufour and Candas, 2007) secondary to a lower evaporation from the skin, a higher $t_{\text {sk }}$ would elevate the ambient air temperature at which the temperature gradient for dry heat loss would be reversed (i.e. to dry heat gain). The values employed in the present model therefore represented the worst-case scenario for estimating the environmental conditions at which a fan would become harmful.

For the "fan on" condition, a dry heat transfer resistance of clothing $\left(R_{c l}\right)$ value of $0.0497 \mathrm{~m}^{2} \mathrm{KW}^{-1}$ (front, facing fan; $50 \%$ of BSA) and $0.0844 \mathrm{~m}^{2} \mathrm{KW}^{-1}$ (rear; $50 \%$ of BSA) was employed in the present model. This value was determined using ISO9920 (2007) and was equivalent to a typical summer ensemble of underwear, a light cotton shirt (with sleeves rolled up to the elbow) and light cotton shorts, and included the insulative effect of air layers 
and alterations in insulation due to different levels of air flow. For the "fan off" condition, an $R_{c l}$ value of $0.1291 \mathrm{~m}^{2} \mathrm{KW}^{-1}$ was used across the whole body.

Air velocity $(v)$ for the "fan on" condition was estimated by employing a free space air velocity of $4.5 \mathrm{~m} \cdot \mathrm{s}^{-1}$, which was determined using a hot-wire anemometer (VelociCalc 9535, TSI Inc, Shoreview MN, USA) during pilot testing of an 18" diameter electrical fan (High velocity orbital air circulator, Whirlpool, Benton Harbor, MI, USA) at waist height set at maximum speed and at a distance of $1.0 \mathrm{~m}$. The air flow profile around the body was then determined using a cylindrical model proposed by Kerslake (1972), and mean $\mathrm{h}_{\mathrm{c}}$ values were then separately determined for the front $\left(16.28 \mathrm{Wm}^{-2} \mathrm{~K}^{-1} ; 50 \%\right.$ of BSA $)$ and back $\left(8.04 \mathrm{Wm}^{-}\right.$ ${ }^{2} \mathrm{~K}^{-1} ; 50 \%$ of BSA) halves of the body. For the "no fan" condition, an air velocity of $0.2 \mathrm{~m} \cdot \mathrm{s}^{-1}$ was employed across the front and back of the body $\left(\mathrm{h}_{\mathrm{c}}=3.16 \mathrm{Wm}^{-2} \mathrm{~K}^{-1}\right)$ which accounted for any effects of natural convection.

A body surface area (BSA) of $1.8 \mathrm{~m}^{2}$ was used for the present model. This BSA is equivalent to an individual with a body mass of $70 \mathrm{~kg}$ and a height of $1.73 \mathrm{~m}$ (DuBois and DuBois, 1916).

Mean radiant temperature $\left(t_{r}\right)$ was assumed to be equal to ambient air temperature since the intent of the model was to assess electric fan use in an indoor environment; a uniform space with no sources of direct radiation (Parsons, 2003).

Respiratory heat loss by convection $\left(C_{r e s}\right)$ and evaporation $\left(E_{r e s}\right)$ : was calculated using equation 6 (ASHRAE, 1997):

$C_{\text {res }}+E_{\text {res }}=\left[0.0014 M\left(34-t_{a}\right)+0.0173 M\left(5.87-P_{a}\right)\right]$

Where: $M$ is metabolic heat production in $\mathrm{Wm}^{-2} ; P_{a}$ is the partial pressure of water vapour of ambient air in $\mathrm{kPa}$; $t_{a}$ is ambient air temperature in ${ }^{\circ} \mathrm{C}$. 


\section{Conceptual heat balance model-Evaporative potential}

The evaporative potential in the ambient environment $\left(E_{\max }\right)$ was calculated using equation 7 (ASHRAE, 1997):

$$
E_{\max }=\frac{\omega\left(P_{s k, s}-P_{a}\right)}{\left[R_{e, c l}+\frac{1}{f_{c l} h_{e}}\right]}
$$

Where; $\omega$ is skin wettedness (i.e. proportion ( 0 through to 1$)$ of BSA covered with sweat (Gagge, 1937); $P_{a}$ the water vapour pressure in the ambient air in $\mathrm{kPa} ; P_{s k, s}$ is the partial water vapour pressure at the skin in $\mathrm{kPa}$ (equal to saturated water vapour pressure at skin temperature $\left(35.5^{\circ} \mathrm{C}\right)$, i.e. $\left.5.78 \mathrm{kPa}\right) ; R_{e, c l}$ is the evaporative resistance of clothing in $\mathrm{m}^{2} \mathrm{kPa}^{-}$

${ }^{1} \mathrm{~W}^{-1} ; f_{c l}$ is clothing area factor [see equation 2]; $h_{e}$ is the evaporative heat transfer coefficient (in $\left.\mathrm{Wm}^{-2} \mathrm{kPa}^{-1}\right)$ calculated using the Lewis Relation $\left(h_{e}=16.5 h_{c}\right)($ Gagge and Gonzalez, 1996).

Critical values for skin wettedness $(\omega)$ were adjusted for fan use and age. Based on the data of McConnell et al. (1924), a critical $\omega$ value of 0.65 was employed for the physiological compensation of all endogenous heat and any exogenous heat in the "fan on" condition in the young adult predictions. This value was reduced to 0.50 for elderly adult predictions to account for the age-related decrements in sweat output of $\sim 25 \%$ observed in hot/dry environments (Anderson and Kenney, 1987) due to a decreased peripheral sensitivity of the sweating mechanism (Dufour and Candas, 2007). For the "fan off" condition, the critical $\omega$ values used for the physiological compensation of endogenous and exogenous heat were 0.85 for young adult predictions (Candas et al, 1979a); this was reduced to 0.65 for the elderly adult predictions. Using the equation reported by Berglund and Gonzalez (1977), the critical $\omega$ value at which an elevated cardiovascular strain (i.e. heart rate) would occur in both 
young and old adults was estimated to be 0.35 in the "fan on" condition. A value of 0.50 was employed for the "fan off" condition.

For the "fan on" condition, an evaporative resistance of clothing $\left(R_{e, c l}\right)$ value of $0.0112 \mathrm{~m}^{2} \mathrm{kPa}^{-1} \mathrm{~W}^{-1}$ (front, facing fan; $50 \%$ of BSA) and $0.0161 \mathrm{~m}^{2} \mathrm{kPa}^{-1} \mathrm{~W}^{-1}$ (rear; $50 \%$ of BSA) were employed. Similarly to $R_{c l}$, this value was determined using ISO 9920 (2007) and was equivalent to a typical summer ensemble, inclusive of air layers. For the "fan off" condition, an $R_{e, c l}$ value of $0.0237 \mathrm{~m}^{2} \mathrm{kPa}^{-1} \mathrm{~W}^{-1}$ was used for the whole body.

\section{Predicted sweat losses}

The rate of sweat production $\left(\mathrm{S}_{\text {req }}\right.$, in $\left.\mathrm{mLh}^{-1}\right)$ to provide the evaporation needed to achieve heat balance was calculated using equation 8 from ISO 7933 (1989):

$S_{r e q}=\frac{\left(\frac{E_{r e q}}{S w_{e f f}} \times 3600\right)}{S w_{\text {latent }}}$

Where; $E_{\text {req }}$ (in Watts) is the rate of evaporation required for heat balance [see equation 1]; $\mathrm{Sw}_{\text {latent }}$ is latent heat of vaporization of sweat $\left(2426 \mathrm{~J} \cdot \mathrm{g}^{-1}\right.$ (Wenger, 1972)); $S w_{\text {eff }}$ is sweating efficiency (i.e. the amount of sweat produced that evaporates) estimated using equation 9 from ISO 7933 (1989):

$S w_{\text {eff }}=1-\frac{\omega_{r e q}{ }^{2}}{2}$

Where; $\omega_{\text {req }}$ is the skin wettedness required for heat balance estimated using equation 10

(Gagge, 1937):

$\omega_{r e q}=\frac{E_{r e q}}{E_{\max }}$ 


\section{Analysis}

Values for $\mathrm{E}_{\text {req }}$ [equation 1] and $\mathrm{E}_{\max }$ [equation 7] were converted into Watts by multiplying values by BSA $\left(1.8 \mathrm{~m}^{2}\right)$. Combinations of air temperature $\left(\mathrm{T}_{\mathrm{a}}\right)$ and relative humidity $(\mathrm{RH})$ were then determined for when;

a) Elevations in cardiovascular strain, i.e. heart rate, would occur (i.e. $\mathrm{E}_{\mathrm{req}}=0.35 \mathrm{E}_{\max }$ (fan on); and $0.50 \mathrm{E}_{\max }$ (fan off);

b) The limit for the physiological compensation of endogenous and exogenous heat is reached (i.e. $\mathrm{E}_{\text {req }}=0.85 \mathrm{E}_{\max }$ (fan off, young adult); and $0.65 \mathrm{E}_{\max }$ (fan off, elderly adult); $\mathrm{E}_{\mathrm{req}}=0.65 \mathrm{E}_{\max }\left(\right.$ fan on, young adult); and $0.50 \mathrm{E}_{\max }$ (fan on, elderly adult);

c) Using an electric fan is actually worse than not using a fan, i.e. the increase in $E_{\text {req }}$ in the "fan on" condition is greater than the increase in $\mathrm{E}_{\max }$ without the required sweat rate $\left(\mathrm{S}_{\text {req }}\right)$ exceeding the limit upper limit of $650 \mathrm{~mL} \cdot \mathrm{h}^{-1}$ for young adults (Malchaire et al. 2000) and $440 \mathrm{~mL} \cdot \mathrm{h}^{-1}$ for elderly adults (Inoue et al. 1991).

\section{RESULTS}

At air temperatures $\left(\mathrm{T}_{\mathrm{a}}\right)$ below skin temperature $\left(\mathrm{T}_{\mathrm{sk}}\right)$, which was set as $35.5^{\circ} \mathrm{C}$ in the present model, the combined rate of dry heat loss via convection and radiation is greater with fan use, relative to no fan use. At $T_{a}$ values greater than $T_{s k}$, the rate of dry of heat loss is negative (i.e. dry heat gain from the environment to the body) and this heat gain is greater with fan use relative to no fan use (Figure 1A). Consequently, the rate of evaporation required for heat balance $\left(E_{\text {req }}\right)$ is greater with fan use when $T_{a}>T_{\text {sk }}$, but lower with fan use when $\mathrm{T}_{\mathrm{a}}<\mathrm{T}_{\mathrm{sk}}$ (Figure $1 \mathrm{~B}$ ). For every $1{ }^{\circ} \mathrm{C}$ that $\mathrm{T}_{\mathrm{a}}$ exceeds $\mathrm{T}_{\mathrm{sk}}$, an electric fan adds approximately $8 \mathrm{~W}$ of dry heat to the body compared to when a fan is not used. Absolute $\mathrm{E}_{\text {req }}$ values are altered slightly by ambient humidity (Figure 1B) secondary to differences in 
estimated respiratory heat loss via evaporation, but the influence of fan use on changes in $\mathrm{E}_{\text {req }}$ with changing $T_{a}$ are the same irrespective of ambient humidity.

The maximum evaporative potential of the ambient environment $\left(\mathrm{E}_{\max }\right)$ is increased greatly by fan use for both young adults (Figure 1C) and the elderly (Figure 1D). However, the difference in $\mathrm{E}_{\max }$ between fan use and no fan use decreases with increasing ambient humidity and increasing ambient air temperature at a fixed relative humidity. Nonetheless, under severe heat wave conditions (e.g. $\left.\sim 40^{\circ} \mathrm{C}, 30 \% \mathrm{RH}\right) \mathrm{E}_{\max }$ for young adults is $101 \mathrm{~W}$ greater with fan use, whereas $\mathrm{E}_{\text {req }}$ is only $37 \mathrm{~W}$ greater with fan use. Even though the increase in $E_{\text {req }}$ with a fan for the elderly is the same as young adults under the same environmental conditions, $\mathrm{E}_{\max }$ is still $79 \mathrm{~W}$ greater with a fan even after accounting for the assumed limited sweat coverage in this population.

The various combinations of $\mathrm{T}_{\mathrm{a}}$ and relative humidity $(\mathrm{RH})$ at which an elevated cardiovascular strain and thermal strain is observed with and without a fan are illustrated in Figure 2. At a low RH (10\%), the $\mathrm{T}_{\mathrm{a}}$ limit for an elevated cardiovascular strain with a fan is $40.1^{\circ} \mathrm{C}$, whereas at a high $\mathrm{RH}(60 \%)$ this limit is $34.1^{\circ} \mathrm{C}$. Furthermore, the estimated $\mathrm{T}_{\mathrm{a}}$ limit for an older adult at which metabolic and passive heat loads can no longer be physiologically compensated by evaporation with maximum skin sweat coverage, with a fan, is $44.2^{\circ} \mathrm{C}$ at $10 \% \mathrm{RH}$ and $35.6^{\circ} \mathrm{C}$ at $60 \% \mathrm{RH}$. For young adults, this limit is raised to $48.0^{\circ} \mathrm{C}$ at $10 \% \mathrm{RH}$ and $36.7^{\circ} \mathrm{C}$ at $60 \% \mathrm{RH}$. Irrespective of $\mathrm{RH}$, the $\mathrm{T}_{\mathrm{a}}$ limit for physiological compensation of core temperature and the onset of cardiovascular strain is approximately 3 to $4^{\circ} \mathrm{C}$ higher with a fan compared to no fan, for both young adults and the elderly. Relative to the peak outdoor conditions reported in ten of the most severe heat waves over the past 20 years (circled numbers), an elevated cardiovascular strain would have been prevented in four cases with a fan, but in no cases without a fan. Furthermore, continuous rises in core temperature would 
have been prevented in six (elderly) and nine (young) cases with a fan, but only one (elderly) and four (young) cases without a fan (Figure 2A-B).

Even above the $\mathrm{T}_{\mathrm{a}}$ limit for the physiological compensation of metabolic and passive heat loads for both the young and the elderly illustrated in Figure 2, electric fan use provides some, albeit marginal, benefits, that is, the rate of body heat storage and therefore the rate of core temperature rise is lower with a fan in comparison to when a fan is not used. Only when the $\mathrm{T}_{\mathrm{a}}$ limits illustrated in Figure 3 are reached, does electric fan use actually become harmful. Under these conditions, which are lower for the elderly on account of their lower maximum skin wettedness, fan use will accelerate the heating of the body and therefore the rate of core temperature rise. These limits were not exceeded once during any of the ten most severe heat waves in the past 20 years (Figure 3).

The predicted sweat losses required to achieve $\mathrm{E}_{\text {req }}$ at each combination of $\mathrm{T}_{\mathrm{a}}$ and $\mathrm{RH}$ are given in Table I. At RH values of $20 \%$ and greater, predicted sweat losses are greater without a fan in comparison to with fan use irrespective of $\mathrm{T}_{\mathrm{a}}$. Sweat losses are greater with fan use only under very hot $\left(>40^{\circ} \mathrm{C}\right)$ and dry $(<10 \% \mathrm{RH})$ environmental conditions. Even in such environments differences in sweat losses are $<25 \mathrm{~mL} /$ hour.

\section{DISCUSSION}

Most current public health guidance suggest that fans are no longer protective at air temperatures that approximately exceed skin temperature, presumably because the gradient for dry heat exchange is reversed and an increase in air flow across the skin would add more environmental heat to the body via convection. For example, the most recent advice from the Centers for Disease Control and Prevention (CDC) in the United States and the National Health Service (NHS) in the United Kingdom states that fans "may not prevent heat-related illness" at air temperatures above $35^{\circ} \mathrm{C}$ (NHS, 2012) or in the "high 90s" ( $\left.{ }^{\circ} \mathrm{F}\right)(\mathrm{CDC}, 2012)$. 
However these limits clearly underestimate the increase in evaporative potential with fan use (Figure 2). Within the parameters of the present model, (i.e. an electric fan creating an air speed of $4.5 \mathrm{~m} / \mathrm{s}$ [equivalent to a typical fan at its highest speed] placed in front of a typical sized person), for every $1^{\circ} \mathrm{C}$ that air temperature exceeds skin temperature, a fan only induces approximately $8 \mathrm{~W}$ of dry heat load. To place this value in context, this additional heat load can be balanced by the evaporation of an extra $\sim 12 \mathrm{~mL}$ of sweat per hour. In fact, the model demonstrates that, irrespective of ambient humidity, fan use provides an additional 3 to $4{ }^{\circ} \mathrm{C}$ of protection against cardiovascular and thermal strain in both young and elderly populations. For example, at a relative humidity of $10 \%$, heat-related elevations in heart rate would be observed at a $\mathrm{T}_{\mathrm{a}}$ of $36.5^{\circ} \mathrm{C}$ without a fan, but not until reaching a $\mathrm{T}_{\mathrm{a}}$ of $40.1^{\circ} \mathrm{C}$ with a fan (Figure 2).

The U.S. Environmental Protection Agency (EPA) seems to provide conflicting guidance on fan use within their own literature. In their Excessive Heat Events Guidebook in Brief (USEPA, 2006a) they advise the public to not "direct the flow of portable electric fans towards yourself when room temperature is hotter than $90^{\circ} \mathrm{F}\left(32.2^{\circ} \mathrm{C}\right) "$. However, in their full length version of the Excessive Heat Events Guidebook (USEPA, 2006b) they state that using an electric fan when the heat index exceeds $99^{\circ} \mathrm{F}\left(37.2^{\circ} \mathrm{C}\right)$ "actually increases the heat stress the body must respond to by blowing air that is warmer than the ideal body temperature over the skin surface". Notwithstanding the results of the present model, both of these statements patently violate fundamental biophysical laws. Even in an elderly population, mean skin temperature during a passive heat stress would not be lower than 35 to $36^{\circ} \mathrm{C}$ (Drinkwater et al. 1982). Therefore, considering that an air temperature of $32.2^{\circ} \mathrm{C}$ would still be at least $3^{\circ} \mathrm{C}$ lower than skin temperature, and that heat energy flows down a temperature gradient, a greater air flow across the skin with an electric fan would actually enhance dry heat loss in addition to assisting the evaporation of sweat from the skin. On the other hand, a heat index 
value of $37.2^{\circ} \mathrm{C}\left(99^{\circ} \mathrm{F}\right)$ represents different $\mathrm{T}_{\mathrm{a}}$ values depending upon relative humidity (e.g. $38.4^{\circ} \mathrm{C}$ at $20 \% \mathrm{RH}$, but $30.7^{\circ} \mathrm{C}$ at $\left.70 \% \mathrm{RH}\right)$. While our model supports the notion that the critical $\mathrm{T}_{\mathrm{a}}$ at which fan use would be harmful is dependent upon ambient humidity (Figure 3), this EPA guideline advises the public to not use fans during evening heat wave conditions (e.g. Washington DC, 2012: $33.0^{\circ} \mathrm{C}, 59 \% \mathrm{RH}$ [heat index: $39.2^{\circ} \mathrm{C}$ ]; Chicago, $1999: 31.1^{\circ} \mathrm{C}$, $82 \% \mathrm{RH}$ [heat index: $41.9^{\circ} \mathrm{C}$ ]) because they will supposedly impose additional heat strain, despite an air temperature that is lower than skin temperature. Even at air temperatures above skin temperature, according to the present model the critical $\mathrm{T}_{\mathrm{a}}$ value at which fans should not be used is much higher (by approximately $7^{\circ} \mathrm{C}$ ) than those suggested by the heat index value issued by the EPA, irrespective of $\mathrm{RH}$, even after accounting for the large reductions in maximum sweat production and skin sweat coverage in the elderly (Figure 3).

Even though cardiovascular failure is the principal cause of death in heat waves, particularly among the elderly (Hajat et al. 2010), it has been suggested that electric fans contribute to additional physiological strain because of a more rapid development of dehydration. For example, the NHS in the United Kingdom clearly state that "fans can cause excess dehydration" and therefore advise the public that fans should be placed "an appropriate distance from people, not aiming it directly on the body" (NHS, 2012). Indeed, if sweat losses are not replaced, progressive changes in hydration status can exacerbate cardiovascular and thermal strain (Harrison, 1986). Furthermore, the greater evaporative heat loss with fans does intuitively require greater sweat losses. However, this assumption only holds if additional air flow does not increase the amount of secreted sweat that actually evaporates (i.e. additional air flow does not improve the evaporative efficiency of sweat $\left.\left(\eta_{\mathrm{sw}}\right)\right)$. Seminal work by Candas (1979a, 1979b) and others (Givoni, 1963; Kerslake, 1963) demonstrated that as $E_{\text {req }}$ approaches $E_{\max }$, an exponential reduction in $\eta_{\text {sw }}$ occurs, that is, progressively more sweat drips off the body and does not contribute to evaporative heat loss 
from the skin. With electric fan use, the additional air flow increases the evaporative heat transfer coefficient $\left(h_{e}\right)$, and subsequently increases $E_{\max }$. Despite $E_{\text {req }}$ increasing slightly with fan use at air temperatures greater than skin temperature, the increase in $E_{\max }$ under most conditions is greater. It follows that under most combinations of $\mathrm{T}_{\mathrm{a}}$ and $\mathrm{RH}, \mathrm{E}_{\text {req }}$ occupies a much smaller proportion of $E_{\max }$ with fan use. As a result, $\eta_{s w}$ is greater and the additional evaporation required for heat balance with a fan is mostly (and in many cases completely) provided by sweat that is already secreted on to the skin surface that would otherwise simply drip off the body if a fan was not used. As such, in all physiologically compensable environments with a relative humidity of $20 \%$ or greater, the predicted sweat losses without a fan are actually 5 to $260 \mathrm{~mL} /$ hour greater than with a fan (Table I). Only in hot $\left(>40^{\circ} \mathrm{C}\right)$ and very dry $(<10 \% \mathrm{RH})$ conditions do fans actually induce greater sweat losses since all the sweat secreted onto the skin surface evaporates (i.e. $\eta_{\mathrm{sw}}=100 \%$ ) even without a fan, due to the high humidity gradient between the skin and ambient air. However, even in the hottest and driest environmental conditions $\left(46^{\circ} \mathrm{C}, 10 \% \mathrm{RH}\right)$ used in the present model, the maximum predicted difference in sweat losses due to fan use was $30 \mathrm{~mL} /$ hour, a difference that could be compensated by the ingestion of an extra 1 cup (i.e. $250 \mathrm{~mL}$ ) of water every 8 hours.

The consequences of using a fan beyond the various critical environmental limits issued by public health agencies, are inconsistent, and potentially have profound effects on behavior during heat waves. Advice that fans will not prevent heat-related illnesses in certain environments, even if very conservative, as seems the case given the present findings, still does not necessarily place individuals at a greater risk since this will encourage them to seek cooler environments or alternative cooling strategies. On the other hand, incorrectly advising the public to stop using fans altogether (USAEPA, 2006b) or modify their use by reducing the convective flow across the skin (NHS, 2012) because of the misplaced notion that a fan will exacerbate thermal strain and dehydration, places individuals at a much greater risk. 
Indeed, even if environmental conditions are such that fans do not prevent heat-related cardiovascular strain or progressive increases in core temperature, fans will still ensure a slower development of physiological strain than without a fan. Only at air temperatures above the critical limits detailed in Figure 3 does fan use actually begin to impose a danger. Relative to the peak outdoor conditions reported during ten of the most severe heat waves over the past two decades, these critical limits for the young or elderly have not been exceeded once. Fan use should therefore never be discouraged in a heat wave. However the public must be aware of when fans do not provide complete protection from physiological strain, so they can seek cooler spaces (e.g. air conditioned public places) or alternative cooling strategies (e.g. immersing in a bathtub filled with cool water). To assist public health messaging a simple chart for young adults and the elderly is provided based upon the present model (Figure 4).

While the model is based on fundamental biophysical principles and physiological parameters defined by the literature, future research is required to validate the present results using human subjects in both hot/humid and hot/dry environmental conditions. Indeed, in very hot and very dry environments, fan use may no longer provide any benefits since all sweat may readily evaporate even without a fan. Potential sources of error in the present model include the critical skin wettedness values that were estimated from the work of McConnell et al. (1924), and Berglund and Gonzalez (1977) who only tested air velocities as high as $2.4 \mathrm{~ms}^{-1}$. Maximum skin wettedness in the elderly has also not been fully defined experimentally with and without forced convection; however this model boundary was chosen to represent to the worst case scenario in the present model, therefore the critical limits for fan use are most likely underestimated. Furthermore, none of the predicted sweat rates in physiologically compensable environments exceeded the maximum absolute sweat rate of an elderly individual suggested by the literature (440 mL/hour (Inoue et al. 1991)). Future studies are also needed to fully define indoor environmental conditions during heat 
waves. Radiant asymmetry due to direct solar radiation on the roof of a building may create hotter indoor conditions on upper levels; indoor sources of moisture may also elevate ambient humidity. Only one fan air speed (maximum) and flow profile was employed in the present evaluation, additional air velocities and air flow direction should be assessed to minimize potential user discomfort. The simultaneous use of other interventions, such as cold fluid ingestion and artificial skin wetting could potentially expand the critical limits for fan use during heat waves, and should therefore also be assessed in future research.

\section{CONCLUSIONS}

Current public health guidelines regarding fan use during heat waves appear flawed. Some guidance partially violates fundamental physical laws, and according to our model, they all greatly underestimate the evaporative power of sweat and exaggerate the increased risk of dehydration with fan use. Irrespective of relative humidity, electric fans increase the critical air temperature at which both an elevated cardiovascular and thermal strain occurs, by approximately 3 to $4^{\circ} \mathrm{C}$ in both the young and elderly. While the absolute air temperature at which these phenomena occur is lower with increasing relative humidity, even above these environmental limits, electric fans are still not harmful, and may provide marginal benefits, up to air temperatures that exceed all of the peak outdoor conditions reported during ten of the most severe heat waves over the past 20 years. The public should therefore not be advised to stop using electric fans during any heat wave. As extreme heat events continue to occur across the globe, a re-evaluation of public health guidelines regarding electric fan use appears necessary to help minimize heat wave related morbidity and mortality. In lieu of any other rational alternatives currently available, the present study provides a simple chart that can be used by healthcare practitioners to educate both elderly and young populations (Figure 4). 


\section{ACKNOWLEDGEMENTS}

Part of this work was originally conducted by Dr. Jay for inclusion in a report for Health Canada. This research was also supported by a Natural Sciences and Engineering Research Council (NSERC) of Canada Discovery Grant (holder: Ollie Jay \#386143-2010). Mr. Cramer is supported by a NSERC PhD Scholarship and a University of Ottawa Excellence Scholarship. We thank Abderrahmane Yagouti for his comments during the initial stages of the project. 


\section{REFERENCES}

Anderson, R.K., Kenney, W.L., 1987. Effect of age on heat-activated sweat gland density and flow during exercise in dry heat. J. Appl. Physiol. 63, 1089-1094.

Berglund, L.G., Gonzalez, R.R., 1977. Evaporation of sweat from sedentary man in humid environments. J. Appl. Physiol. 42, 767-772.

Candas, V., Libert, J.P., Vogt, J.J., 1979a. Human skin wettedness and evaporative efficiency of sweating. J. Appl. Physiol. 46, 522-528.

Candas, V., Libert, J.P., Vogt, J.J., 1979b. Influence of air velocity and heat acclimation on human skin wettedness and sweating efficiency. J. Appl. Physiol. 47, 1194-1200.

CDC, 2012. Centers for Disease Control and Prevention (CDC) Extreme Heat: A Prevention Guide to Promote Your Personal Health and Safety. http://emergency.cdc.gov/disasters/extremeheat/heat_guide-page-2.asp. Accessed July 31 2013

de Dear, R.J., Arens, E., Hui, Z., Oguro, M., 1997. Convective and radiative heat transfer coefficients for individual human body segments. Int .J. Biometeorol. 40, 141-156.

Drinkwater, B.L., Bedi, J.F., Loucks, A.B., Roche, S., Horvath, S.M., 1982. Sweating sensitivity and capacity of women in relation to age. J. Appl. Physiol. 53, 671-676.

DuBois, D., DuBois, E.F., 1916. A formula to estimate surface area if height and weight are known. Arch. Internal Med. 17, 863.

Dufour, A., Candas, V., 2007. Ageing and thermal responses during passive heat exposure: sweating and sensory aspects. Eur. J. Appl. Physiol. 100, 19-26.

Fanger, P.O., 1967. Calculation of thermal comfort: Introduction of basic comfort equation. ASHRAE Transactions. 73, Part 2.

Gagge, A.P., 1937. A new physiology variable associated with sensible and insensible perspiration. Am. J. Physiol. 120, 277-287.

Gagge, A.P., Gonzalez, R.R., 1996. Mechanisms of heat exchange, in: Fregly, M.J., Blatteis, C.M. (Eds.), Handbook of Physiology. Environmental Physiology, vol I, Chapt. 4. American Physiological Society, Bethesda, pp. 45-84. 
Givoni, B., 1963. Estimation of the Effect of Climate on Man: Development of a New Thermal Index. Research Report to UNESCO. Israel Institute of Technology, Haifa, Israel

Gupta, S., Carmichael, C., Simpson, C., Clarke, M.J., Allen, C., Gao, Y., Chan, E.Y., Murray, V., 2012. Electric fans for reducing adverse health impacts in heatwaves. Cochrane Database Syst. Rev. 7. doi:10.1002/14651858.CD009888.pub2

Hajat, S., O'Connor, M., Kosatsky, T., 2010. Health effects of hot weather: from awareness of risk factors to effective health protection. Lancet. 375, 856-863.

Harrison, M.H., 1986, Heat and exercise. Effects on blood volume. Sports Med. 3, 214-223.

Inoue, Y., Nakao, M., Araki, T., Murakami, H., 1991. Regional differences in the sweating responses of older and younger men. J. Appl. Physiol. 71, 2453-2459.

ISO 7933, 1989, Hot environments: Analytical determination and interpretation of thermal stress using calculation of required sweat rate. International Standards Organization, Geneva

ISO 9920, 2007, Ergonomics of the thermal environment - estimation of the thermal insulation and evaporative resistance of a clothing ensemble. International Standards Organization, Geneva

Kenney, W.L., Hodgson, J.L., 1987. Heat tolerance, thermoregulation and ageing. Sports Med. 4, 446-456.

Kerslake, D.M., 1963. Errors arising from the use of mean heat exchange coefficients in the calculation of the heat exchanges of a cylindrical body in a traverse wind, in: Hardy, J.D. (Ed.) Temperature: Its Measurement and Control in Science and Industry, vol 3. Reinhold, New York, pp 183-189.

Kerslake, D.M., 1972, The Stress of Hot Environments. Cambridge University Press, Cambridge.

Malchaire, J., Kampmann, B., Havenith, G., Mehnert, P., Gebhardt, H.J., 2000, Criteria for estimating acceptable exposure times in hot working environments: a review. Int. Arch. Occup. Environ. Health. 73, 215-220. 
McConnell, W.J., Houghten, F.C., Yagloglou, C.P., 1924. Air motion - high temperatures and various humidities - reactions on human beings. Trans. Am. Soc. Heat. Vent. Eng. 30, 199-224.

McCullough, E.A., Jones, B.W., 1984. A comprehensive data base for estimating clothing insulation. IER Technical Report 84-01. ASHRAE, 411-RP.

Mitchell, D., 1974. Convective heat loss from man and other animals. in: Monteith J.L., Mount, L.E., (Eds.) Heat Loss from Animals and Man. Butterworths, London.

NHS, 2012. Heatwave plan for England: Supporting vulnerable people before and during a heatwave. National Health Service.

https:/www.gov.uk/government/uploads/system/uploads/attachment_data/file/216526/dh 134156.pdf. Accessed July 312013

Parsons, K.C., 2003. Human Thermal Environments, second ed. Taylor \& Francis, London.

USEPA, 2006a. Excessive Heat Events Guidebook in Brief (EPA 430-B-06-006).

http://www.epa.gov/heatisld/about/pdf/EHEguide-brief final.pdf. Accessed July 312013

USEPA, 2006b, Excessive Heat Events Guidebook (EPA 430-B-06-005).

http://www.epa.gov/heatisld/about/pdf/EHEguide_final.pdf. Accessed July 312013

Wenger, C.B., 1972, Heat of evaporation of sweat: thermodynamic considerations. J. Appl. Physiol. 32, 456-459.

Wolfe, R.M., 2003, Death in heat waves: beware of fans. BMJ. 327, 1228.

Zahorska-Markiewicz, B., 1982, Thermal and metabolic responses to heat exposure in obesity. Eur. J. Appl. Physiol. Occup. Physiol. 48, 379-385. 
Table I. Predicted whole-body sweat losses at different combinations of ambient air temperature $\left(\mathrm{T}_{\mathrm{a}}\right)$ and relative humidity with (FAN) and without (NO FAN) an electric fan.

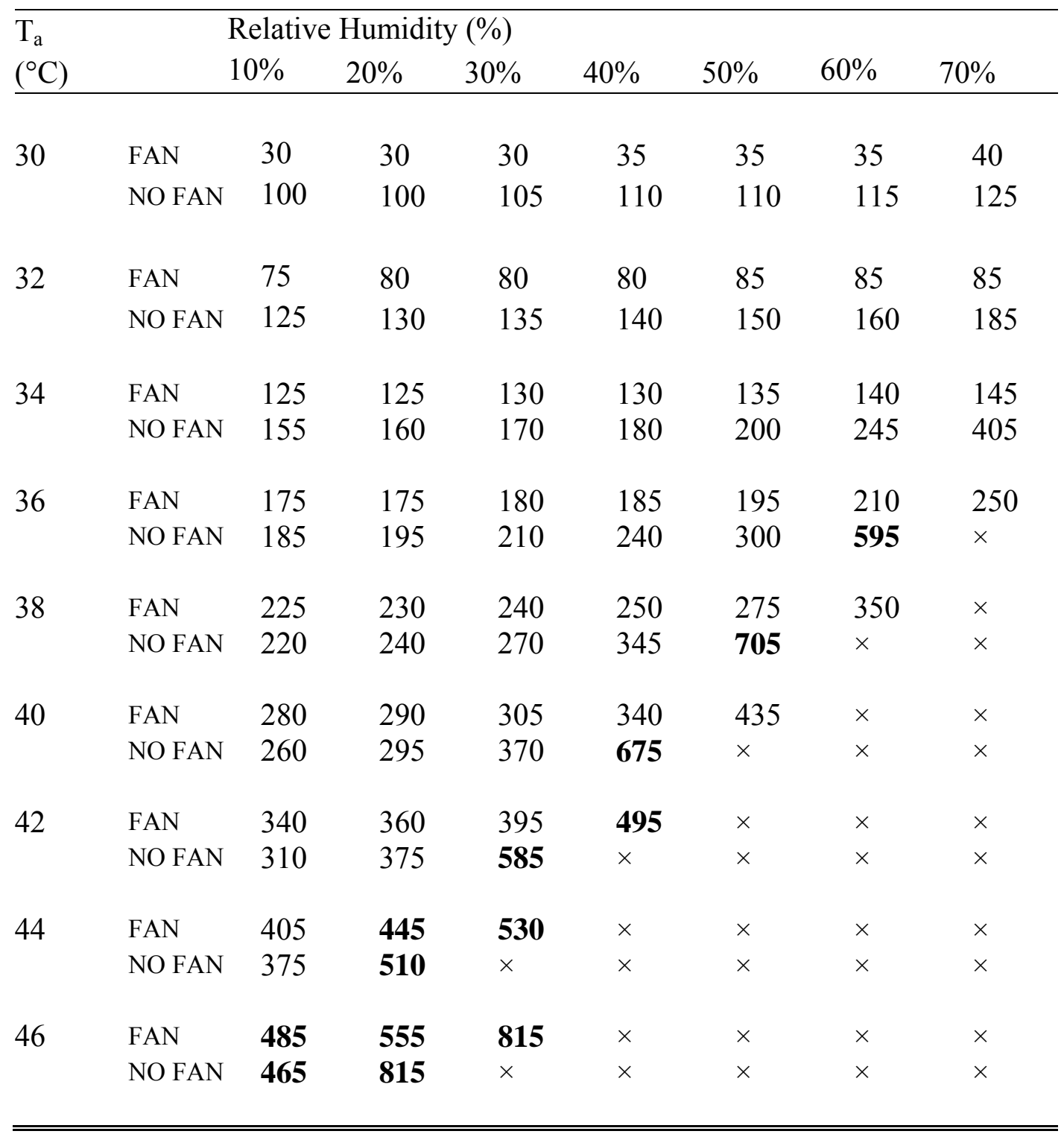

Values expressed in $\mathrm{mL}$ per hour. A cross $(\times)$ indicates a maximum resting sweat rate ( $\sim 650 \mathrm{~mL}$ per hour (Malchaire et al. 2000$))$ is reached in healthy adults. Values in bold indicate that the maximum resting sweat rate in an elderly population (i.e. $\sim 440 \mathrm{~mL}$ per hour) has been exceeded (Inoue et al. 1991). 

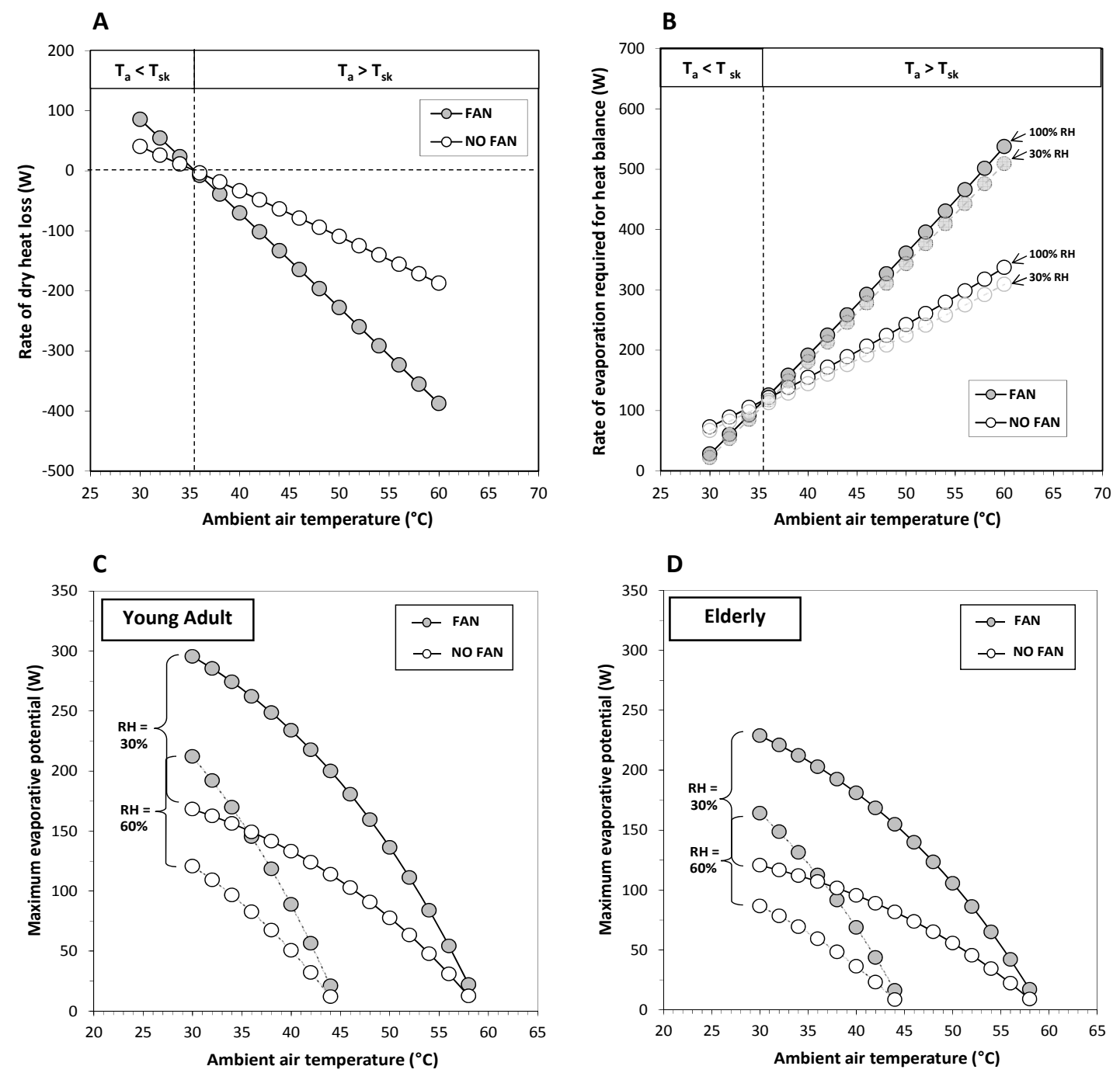

Figure 1. The predicted values with (FAN) and without (NO FAN) an electric fan with increasing air temperature for, the combined rate of dry heat loss via convection and radiation (Panel A), the rate of evaporation required for heat balance $\left(E_{\text {req }}\right)($ Panel B), and the maximum evaporative potential $\left(\mathrm{E}_{\max }\right)$ for a young adult (Panel $\mathrm{C}$ ) and an elderly adult (Panel D). 

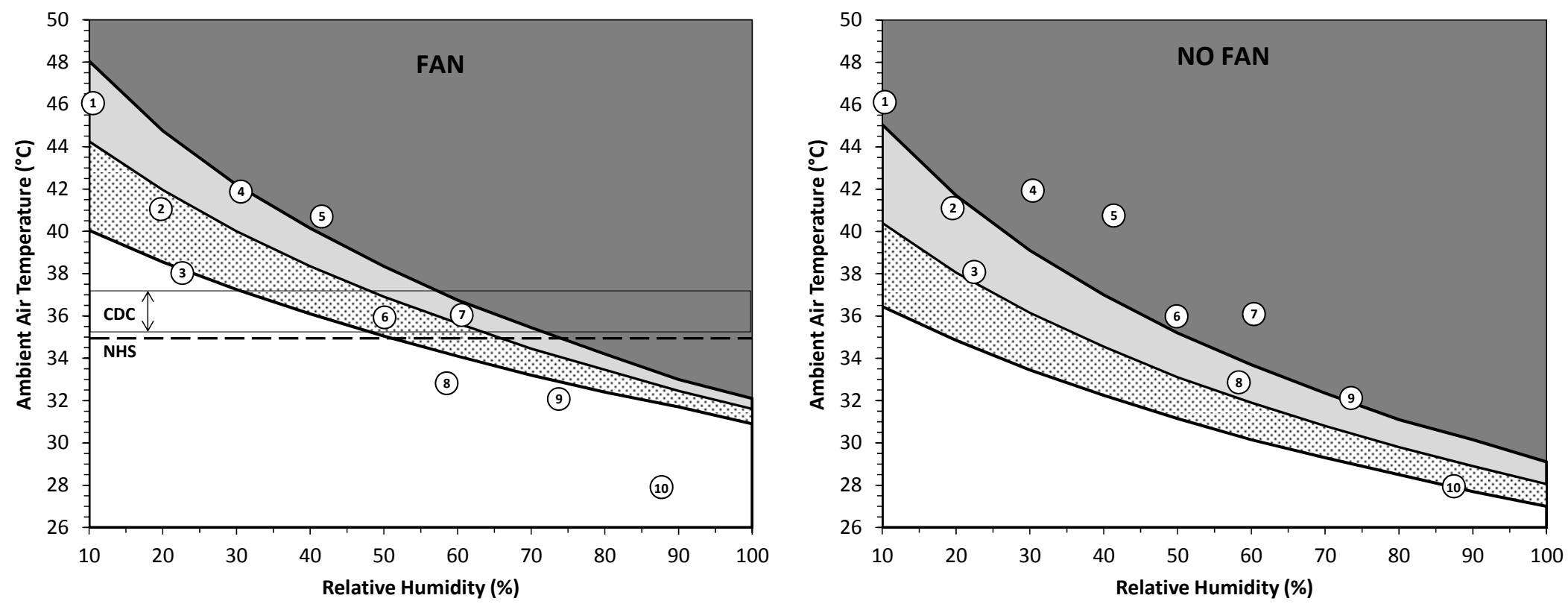

Figure 2. Predicted critical environmental limits for FAN and NO FAN conditions. White area $\boldsymbol{\square}$ indicates no elevation in cardiovascular strain; Dotted area $\mathbf{D}$ indicates an elevated cardiovascular strain; Light grey area $\boldsymbol{\square}$ indicates that the physiological compensation endogenous and exogenous heat would not be possible in the elderly; Dark grey area $\square$ indicates that the physiological compensation of endogenous and exogenous heat would not be possible in all individuals. Peak hourly outdoor heat wave conditions for: Sydney, 2013 (1); Washington DC, 2012 (2); Paris, 2003 (3); Newark, 2011 (4); Chicago, 1995 (5); New York, 2006 (6); Chicago, 1999 (7); Washington DC, (night) 2012 (8); Chicago (night), 1999 (9); Paris (night), 2003 (10). Critical environmental limits at which electric fans are stated to be no longer protective by the Centers for Disease Control and Prevention (CDC, 2012) in the United States - range indicated by solid lines; and the National Health Service (NHS, 2012) in the United Kingdom - indicated by dashed line. 


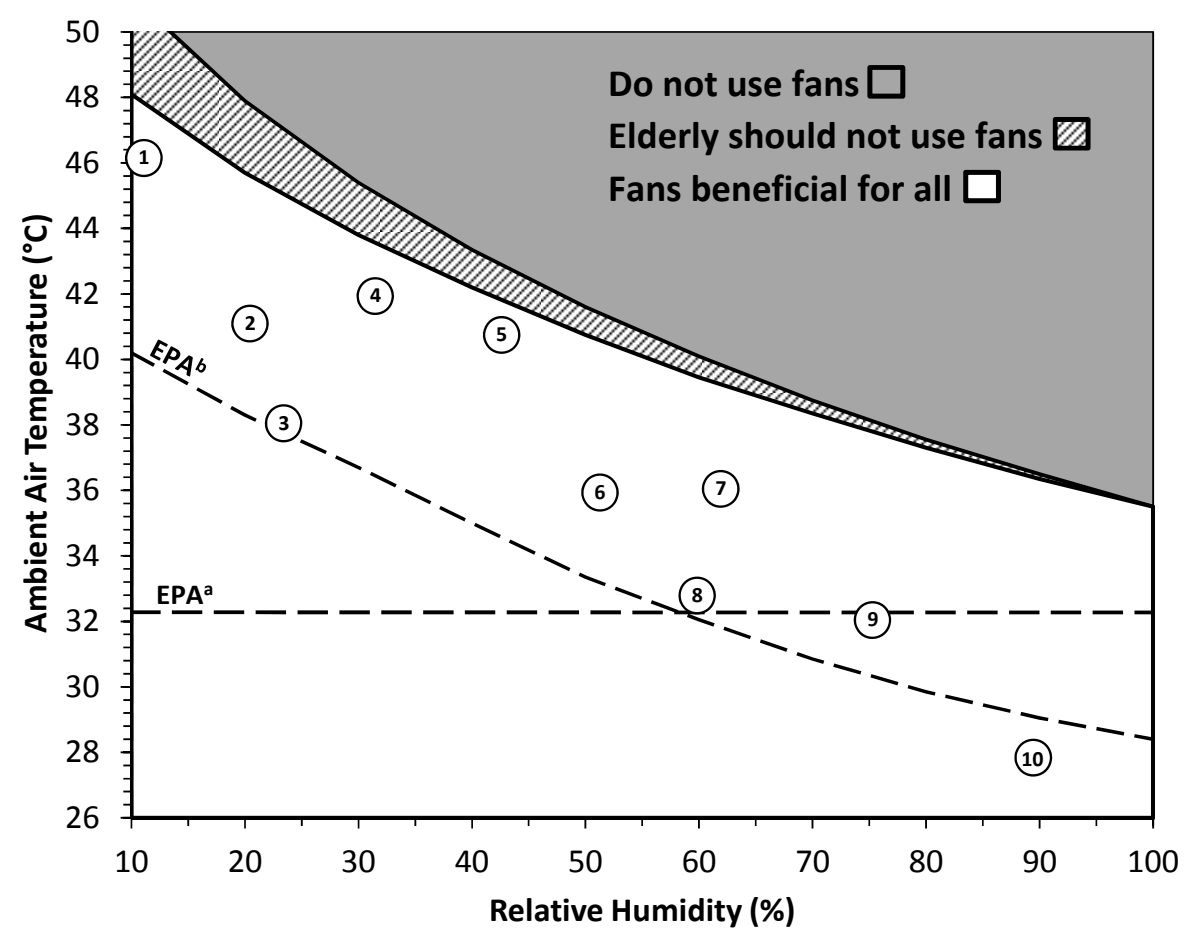

Figure 3. Predicted critical environmental limits at which electric fan use becomes harmful. Peak hourly outdoor heat wave conditions for: Sydney, 2013 (1); Washington DC, 2012 (2); Paris, 2003 (3); Newark, 2011 (4); Chicago, 1995 (5); New York, 2006 (6); Chicago, 1999 (7); Washington DC, (night) 2012 (8); Chicago (night), 1999 (9); Paris (night), 2003 (10). Dashed lines indicate existing environmental limits issued by the US Environmental Protection Agency (EPA ${ }^{\mathrm{a}}$ (USEPA, 2006a); EPA $^{\mathrm{b}}$ (USEPA, 2006b)) 

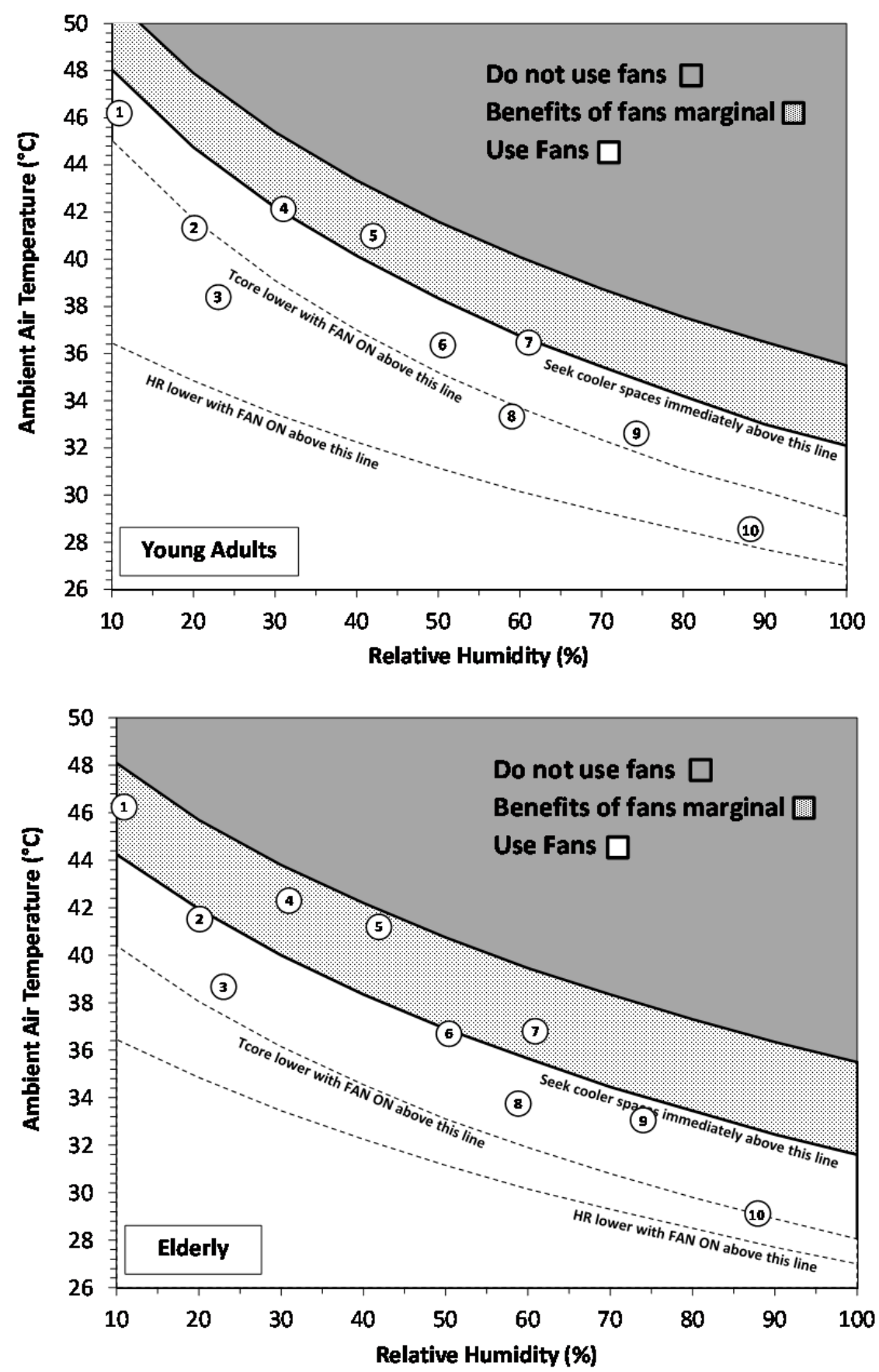

Figure 4. Predicted critical environmental limits that electric fans are: a) advised (white area); b) advised, but cooler spaces must be sought immediately as heat stroke will eventually occur (dotted area); and c) not advised, since fans will accelerate the onset of heat stroke (grey area). Peak hourly outdoor heat wave conditions for: Sydney, 2013 (1); Washington DC, 2012 (2); Paris, 2003 (3); Newark, 2011 (4); Chicago, 1995 (5); New York, 2006 (6); Chicago, 1999 (7); Washington DC, (night) 2012 (8); Chicago (night), 1999 (9); Paris (night), 2003 (10). $\mathrm{T}_{\text {core }}$, core temperature; HR, heart rate. 